\title{
The Thermodynamic Stability of Adamantylideneadamantane and Its Proton- and Electron-Exchanges. Comparison with Simple Alkenes
}

\author{
José-Luis M. Abboud, ${ }^{* 1}$ Ibon Alkorta, ${ }^{* 2}$ Juan Z. Dávalos, ${ }^{* 3}$ Ilmar A. Koppel, ${ }^{4}$ Ivar Koppel, ${ }^{* 5}$ \\ Dieter Lenoir, ${ }^{* 6}$ Sonia Martínez, ${ }^{7}$ and Masaaki Mishima*1 \\ ${ }^{1}$ Institute for Materials Chemistry and Engineering, Kyushu University, 744 Motooka, Nishi-ku, Fukuoka 819-0395 \\ ${ }^{2}$ Institute of Medical Chemistry, CSIC. c/ Juan de la Cierva, 3, E-28006, Madrid, Spain \\ ${ }^{3}$ Institute of Physical Chemistry Rocasolano. c/ Serrano, 119, E-28003, Madrid, Spain \\ ${ }^{4}$ Institute of Chemistry, University of Tartu Ravila 14a, 50411, Tartu, Estonia \\ ${ }^{5}$ Institute of Computer Sciences, University of Tartu, Liivi 2, 50409 Tartu, Estonia \\ ${ }^{6}$ Institute of Ecological Chemistry, Helmholtz-Center Munich, D-85758 Neuherg, Germany \\ ${ }^{7}$ Centro de Cálculo Científico del CSIC. Secretaría General Adjunta de Informática c/ Pinar 19, 28006 Madrid, Spain \\ E-mail: abboud@ms.ifoc.kyushu-u.ac.jp, mishima@ms.ifoc.kyushu-u.ac.jp
}

Received: January 21, 2016; Accepted: March 28, 2016; Web Released: April 6, 2016
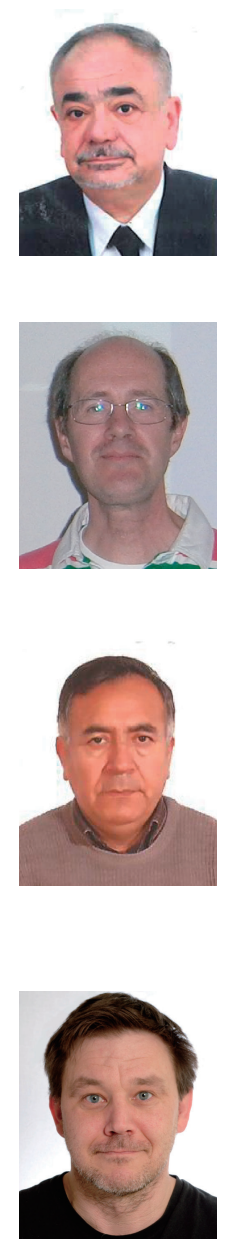

\section{José-Luis M. Abboud}

He received his Ph.D. from the University of Bordeaux (France) under the supervision of Prof. Louis Bellon (1970). He was a UNESCO post-doctoral fellow at Tokyo Institute of Technology (1971-2) under Prof. Y. Hatano, Teaching and research at University of Marrakech (1972-4), and Research Associate with Prof. E. M. Arnett (University of Pittsburgh) (1974-5) and with Prof. R. W. Taft (UCl, California) (1975-8). He was a Research Professor at CSIC, Madrid (1983-2012). His interests are solvent effects in organic chemistry, gas-phase ion chemistry, thermodynamics and thermochemistry of strained compounds.

\section{Ibon Alkorta}

Profesor Científico at the Instituto de Química Médica. He received his Ph.D. degree from the Universidad Autónoma de Madrid in 1990 and was a post-doctoral fellow with Dr. Hugo Villar at Molecular Research Institute, Palo Alto, California (1991-1993). His major research is the theoretical and computational chemistry: chiral recognition, noncovalent interactions, NMR theoretical calculations, medicinal, and bioorganic studies.

\begin{abstract}
Juan Z. Dávalos Prado
Research Scientist of Instituto Química-Física "Rocasolano"-CSIC, Madrid-Spain. He received his Ph.D. degree from Universidad Autónoma de Madrid the Universidad Autónoma de Madrid in 1992. He applies theoretical (ab initio, DFT) and experimental techniques (Mass Spectrometry, Calorimetric and Photoionization tools) to the study of thermodynamic stabilities and structure-reactivity relationships, in the gas phase, of ions, radicals and neutral species with fundamental, biological, technological, and environmental relevance.
\end{abstract}

\section{Ivar Koppel}

Principal investigator, Centre of Strategical Competence, Tartu University. He received his Ph.D. degree from Tartu University in 1994. He was a Visiting Scientist, 'Rocasolano' Institue, C.S.I.C., Madrid, with Prof. J.-L. M. Abboud, A. v. Humboldt Scholar with Prof. P. v. R. Schleyer, University Erlangen-Nürnberg, and a Visiting Professor, University of Nice, with Prof. J.-F. Gal. The main areas of present research involve the study of superbasicity and superacidity using quantum chemical methods and the development and application of new highly parallel methods for scientific computing, the advancement of Open Data in science, and European Science Cloud initiative. 


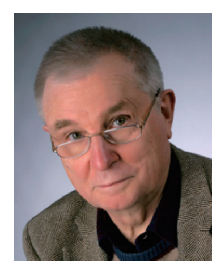

\section{Dieter Lenoir}

Visiting Scientist at Helmholtz-Center Muenchen. He received his Ph.D. degree from Bonn University in 1968. NIH Postdoctoral Fellow at Princeton University (Prof. P. v. R. Schleyer), Lecturer at the Technical University Munich. He was a group leader for incineration research at the GSF-National Research Center, Neuherberg, until 2000. His current interests: halogenated micropollutants in incinerations, mechanisms of formation, inhibition of PCDD/F, brominated flame retardants and alternatives on phosphorus, basis environmental organic chemistry, carbocations, strained organic compounds, mechanism of electrophilic brominations of alkenes and alkynes, photochemistry of stilbenes, sustainable chemistry, green syntheses, sustainable oxidations, mass balances.

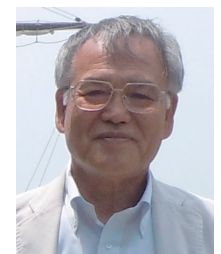

\section{Masaaki Mishima}

Professor Emeritus, Kyushu University. He received his Ph.D. degree from Osaka University (Prof. Y. Yukawa) in 1976 and worked as a Research Associate at Kyushu University and Institute for Molecular Science and as a Visiting Scientist at University of California, Irvine (Prof. R. W. Taft) (1981-1983). He was an Associate Professor and a Full Professor at Kyushu University until 2010. His interests are structurereactivity relationship in organic chemistry, gas-phase ion chemistry, solvent effects on organic reaction, ion cyclotron resonance spectrometry, interplay between experiments and computational studies.

\begin{abstract}
We report herein the results of an experimental and computational study of adamantylideneadamantane (1) and a variety of substituted ethylenic hydrocarbons. The standard enthalpy of formation in the gas phase as well as the gas-phase basicity $(G A)$ of 1 were experimentally determined for the first time, respectively by calorimetric techniques and FT-ICR spectrometry. In parallel, computational studies at the MP2/ $6-311+\mathrm{G}(\mathrm{d}, \mathrm{p}), \mathrm{G} 3(\mathrm{MP} 2)$, and G3 levels were performed on the neutral (1) and protonated $\left(1 \mathrm{H}^{+}\right)$. The agreement with experimental results was very good. The structures of $\mathbf{1}$ and $1 \mathrm{H}^{+}$were subject to treatment by "Atoms in Molecules" in order to assess the characteristics of the closest $\mathrm{H} \cdots \mathrm{H}$ interactions involving both adamantane moieties. Also, the secondorder perturbation analysis within the Natural Bond Orbital Theory methodology shows four degenerate charge-transfer interactions between the $\sigma \mathrm{C}-\mathrm{H}$ bond of one of the adamantyl subunits towards the $\sigma^{*} \mathrm{C}-\mathrm{H}$ of the other adamantyl subunit. The standard enthalpies of formation of new adamantyl compounds were obtained using our experimental data. The computational study of a variety of ethylenic compounds including cyclohexylidenecyclohexane and several alkyl-substituted ethylenes using isodesmic and homodesmotic reactions was carried out. This study was extended to their proton affinities and gas-phase basicities.
\end{abstract}

\section{Introduction}

Adamantane, $\mathrm{C}_{10} \mathrm{H}_{16}$, is the basic building block which leads to elaborations of the diamonoid family., ${ }^{1,2}$ Poly(1,3-adamantane) stable polymers have been reported recently. ${ }^{3}$ This work focuses on the cognate, $D_{2 h}$ symmetric adamantylideneadamantane (1, $\mathrm{Ad}=\mathrm{Ad}, \mathrm{C}_{20} \mathrm{H}_{28}$, Figure 1), in which a tetrasubstituted ethylenic linkage combines two adamantanes.

We have reported an experimental and computational study on the degenerate electron exchange between cage hydrocarbons and the corresponding radical cations. ${ }^{4}$

Here we extend this work to the thermodynamics of neutral, protonated, or ionized $\mathbf{1}$.

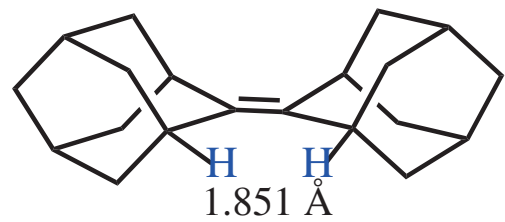

Figure 1. Structure of adamantylideneadamantane. One of the two equal, shortest $\mathrm{H}$...H distance is shown.

As regards 1, X-ray studies 5 show that the length of the ethylenic $\mathrm{C}=\mathrm{C}(1.344 \AA)$ and other bond lengths are consistent with 1 being a strain-free olefin except for the internal strain of the adamantane moieties ${ }^{6}$ and the close approach $(1.851 \AA)$ of the hydrogen atoms shown in Figure $1^{7}$ (only one of the two pairs is shown). This nicely agrees with the geometries computed at the B3LYP/6-31G*, ${ }^{8}$ B3LYP/aug-cc-pVTZ ${ }^{4}$ as well as MP2(Full)/6-31G* and MP2/6-311+G** levels (this work).

The radical cation $\mathbf{1}^{+\bullet}$, forms readily as a long-lived oneelectron, two-center $\pi$-bonded species ${ }^{9}$ in different chemical processes, and has been characterized by near-UV-vis spectroscopy. ${ }^{10,11}$ Known in the gas phase, ${ }^{4} \mathbf{1}^{+\bullet}$ also has been identified in the epoxidation of $\mathbf{1}$ (directly by $\mathrm{NO}_{2}{ }^{12}$ or by $\mathrm{O}_{2}$ catalyzed with nitrogen oxides and protic solvents). ${ }^{13,14}$ The experimental vertical ionization energy of $\mathbf{1}$ is relatively small, $7.84 \mathrm{eV}^{15}$ This ease of oxidation and the protective shielding of the ethylenic bond by the four $\beta-\mathrm{C}-\mathrm{H}$ groups enrich the chemistry of $\mathbf{1}{ }^{16}$ Substitution of the $\alpha-\mathrm{C}-\mathrm{H}$ hydrogens by alkyl or phenyl groups affects the planarity and strains the ethylenic moiety of these derivatives. ${ }^{17,18}$

This work is aimed at gaining fundamental physicochemical information on $\mathbf{1}$ in the gas phase since this compound is an appropriate benchmark for the study of structural effects on the reactivity of its derivatives. In particular, we experimentally determined its standard enthalpy of formation, $\Delta_{\mathrm{f}} H^{\circ} \mathrm{m}(\mathbf{1})$ in the gas phase as well as its gas-phase basicity, $G B(\mathbf{1})$, the negative of the standard Gibbs energy change for reaction (1): ${ }^{19}$

$$
\mathbf{1}(\mathrm{g})+\mathrm{H}^{+}(\mathrm{g}) \rightarrow \mathbf{1 H}^{+}(\mathrm{g}) \quad \Delta_{\mathrm{r}} G^{\circ}{ }_{\mathrm{m}}(1)=-G B(\mathbf{1})
$$


Also carried out were computational studies on these properties and calculation of the adiabatic and vertical ionization energies of 1 .

\section{Experimental}

The Standard Enthalpy of Formation of 1. The enthalpy of formation in the gas phase at $T=298.15 \mathrm{~K}$ of $\mathbf{1}$ was derived from the experimental value of the standard enthalpy of formation in the crystalline state, $\Delta_{\mathrm{f}} H_{\mathrm{m}}^{\circ}(\mathrm{cr}, 298.15 \mathrm{~K})$ carried out by combustion calorimetry, and the standard enthalpy of sublimation $\Delta_{\text {sub }} H^{\circ}(298.15 \mathrm{~K})$ by the measurement of their vapor pressures. The energy of combustion, $\Delta_{\mathrm{c}} u=$ $-(43266.57 \pm 3.1) \mathrm{J} \mathrm{g}^{-1}$ per unity of mass, has been determined using a static bomb calorimeter (energy equivalent of calorimeter, $\left.\varepsilon=14262.6 \pm 2.5 \mathrm{~J} \mathrm{~K}^{-1}\right){ }^{20}$ The vapor pressures were determined at different temperatures in the interval of temperature (324.56-357.54) K by the Knudsen effusion technique ${ }^{21-23}$ and the enthalpy of sublimation at the mean temperature, $\Delta_{\text {sub }} H^{\circ}{ }_{\mathrm{m}}\left(T_{\mathrm{m}}=341.05 \mathrm{~K}\right)=(98.6 \pm 2.7) \mathrm{kJ} \mathrm{mol}^{-1}$, was deduced from Clausius-Clapeyron equation. This value was adjusted at $T=298.15 \mathrm{~K}$ using eq 2 :

$$
\begin{aligned}
& \Delta_{\text {sub }} H_{\mathrm{m}}^{\circ}(T=298.15 \mathrm{~K}) \\
& \quad=\Delta_{\text {sub }} H_{\mathrm{m}}^{\circ}\left(T_{\mathrm{m}}\right)+\int_{T_{\mathrm{m}}}^{298.15}\left[C_{p, \mathrm{~m}}^{\circ}(\mathrm{g})-C_{p, \mathrm{~m}}^{\circ}(\mathrm{cr})\right] \mathrm{d} T \\
& =102.2 \mathrm{~kJ} \mathrm{~mol}^{-1}
\end{aligned}
$$

where the heat capacity of the gas phase, $C_{p, \mathrm{~m}}^{\circ}(\mathrm{g})=-42.9+$ $8.3 \times 10^{-1} T+5.0 \times 10^{-4} T^{2}$, was calculated from molecular vibrational contributions, and the heat capacity of the solid phase, $C_{p, \mathrm{~m}}^{\circ}(\mathrm{cr})=68.9+2.95 \times 10^{-1} T+1.9 \times 10^{-3} T^{2}$, was obtained from experimental measurements of heat capacities using differential scanning calorimetry. From the experimental results, the standard molar enthalpies of combustion, sublimation, and formation in the crystalline and gaseous state at temperature of $298.15 \mathrm{~K}$ were derived and are reported in Table 1.

Experimental Determination of the Gas-Phase Basicity of 1. Fourier transform ion-cyclotron resonance spectrometry (FT-ICR spectrometry) was performed on a modified Bruker CMS-47 FT-ICR mass spectrometer used in recent studies. ${ }^{24,25}$ Detailed descriptions of the technique are given in refs 26-32. The original instrument is described in ref 26. The spectrometer is linked to an Omega Data Station (IonSpec, CA). The magnetic field strength of the superconducting magnet is $4.7 \mathrm{~T}$ (Tesla). The cell temperature is $321 \pm 10 \mathrm{~K}$.

The main process studied was of the form of reaction (3):

$$
\mathrm{B}_{\mathrm{ref}} \mathrm{H}^{+}(\mathrm{g})+\mathrm{B}(\mathrm{g}) \rightarrow \mathrm{BH}^{+}(\mathrm{g})+\mathrm{B}_{\mathrm{ref}}(\mathrm{g}) \quad K_{p}(3) \quad \Delta_{\mathrm{r}} G^{\circ}{ }_{\mathrm{m}}(3)
$$

where $\mathrm{B}_{\text {ref }}$ is a base of known $G B$ and $\mathrm{B}$ is the base under study. Mixtures of neutral $\mathrm{B}_{\text {ref }}$ and $\mathrm{B}$ (partial pressures in the range

Table 1. Standard molar enthalpies of combustion, sublimation, and formation in the crystalline and gaseous states at $T=298.15 \mathrm{~K}$ and $p^{\circ}=101.325 \mathrm{kP}$

\begin{tabular}{llll}
\hline$\Delta_{\mathrm{c}} H^{\circ}{ }_{\mathrm{m}}^{\mathrm{a})}$ & $\Delta_{\mathrm{f}} H_{\mathrm{m}}^{\circ}(\mathrm{cr})^{\mathrm{a})}$ & $\Delta_{\mathrm{sub}} H_{\mathrm{m}}^{\circ}{ }^{\mathrm{a})}$ & $\Delta_{\mathrm{f}} H_{\mathrm{m}}^{\circ}(\mathrm{g})^{\mathrm{a})}$ \\
\hline $11631.7 \pm 5.1$ & $-240.2 \pm 5.8$ & $102.2 \pm 2.8$ & $-138.0 \pm 6.4$ \\
\hline
\end{tabular}

a) All values in $\mathrm{kJ} \mathrm{mol}^{-1}$.
$10^{-8}-10^{-7}$ mbar) and Ar (cooling gas, pressures of $5 \times 10^{-7}$ to $8 \times 10^{-7}$ mbar) are ionized with an electron beam of the lowest possible ionization energy. Generally, ionic fragments act as proton sources and lead to the formation of $\mathrm{B}_{\text {ref }} \mathrm{H}^{+}$and $\mathrm{BH}^{+}$. The system is allowed to evolve during times of up to $60-90 \mathrm{~s}$. In the case of a normal equilibrium, the ratio of intensities of these ions, $I_{\mathrm{BH}^{+}} / I_{\mathrm{Bref}_{\mathrm{re}} \mathrm{H}^{+}}$stabilizes after some time and is taken as the ratio of the partial pressures of the corresponding ionic species, namely $P_{\mathrm{BH}^{+}} / P_{\mathrm{B}_{\mathrm{ref}} \mathrm{H}^{+}}$. The equilibrium constant $K_{p}(3)$ is then given by eq 4 :

$$
K_{p}(3)=\left(P_{\mathrm{BH}^{+}} / P_{\mathrm{B}_{\mathrm{ref}} \mathrm{H}^{+}}\right) \times\left(P_{\mathrm{B}_{\mathrm{ref}}} / P_{\mathrm{B}}\right)
$$

and the gas-phase basicity of $\mathrm{B}$ is given by eq 5 :

$$
G B(\mathrm{~B})=G B\left(\mathrm{~B}_{\mathrm{ref}}\right)+R T \ln K_{p}
$$

In what follows, the base B of unknown basicity is $\mathbf{1}$. As usual, herein we used several reference bases and different pressure ratios for each of them. Ion-selection experiments showed the reversibility of the proton exchange between 1 and $B_{\text {ref. }}$.

We failed to observe a clean protonation of 1 using reference bases stronger than pyrazine. We observed fast, unequivocal protonation of $\mathbf{1}$ using the protonated forms of the following bases ( $G B \mathrm{~s}$ in $\mathrm{kJ} \mathrm{mol}^{-1}$ given in parentheses): $\mathrm{HCO}_{2}-n-\mathrm{C}_{3} \mathrm{H}_{7}$ (773.9), $\left(\mathrm{CH}_{3}\right)_{2} \mathrm{CO}$ (782.1), THF (794.7), $\mathrm{C}_{2} \mathrm{H}_{5} \mathrm{CO}_{2} \mathrm{CH}_{3}$ (810.8), $\mathrm{CH}_{3} \mathrm{SC}_{2} \mathrm{H}_{5}$ (815.3). In all these cases, ion-selection experiments showed the reversibility of the proton exchange.

The strongest bases leading to a constant ratio of $\left(P_{1 \mathrm{H}^{+}} /\right.$ $P_{\mathrm{B}_{\text {ref }} \mathrm{H}^{+}}$), i.e., the ratio of the ion intensities of $1 \mathrm{H}^{+}$and $\mathrm{B}_{\text {ref }} \mathrm{H}^{+}$, over a period of at least $30 \mathrm{~s}$ are presented in Table 2 . In all these cases, ion-selection experiments showed the reversibility of the proton exchange.

We take the average value, $842.0 \mathrm{~kJ} \mathrm{~mol}^{-1}$ as the experimental $G B(\mathbf{1})$. In general, the uncertainty on the gas-phase basicity of a given base is taken as ca. $8.2 \mathrm{~kJ} \mathrm{~mol}^{-1} .33$ Our result, $6.3 \mathrm{~kJ} \mathrm{~mol}^{-1}$ seems quite consistent with it.

\section{Computational Results and Discussion}

Computations at both the MP2/6-311+G(d,p) ${ }^{34}$ and $G 3^{35}$ levels were applied to most of the relevant species with few exceptions. In the case of $\mathbf{1}$, we used both G3 and G3(MP2). ${ }^{36}$ Raw results are given in the Supporting Information Section.

The Standard Enthalpy of Formation of 1, $\Delta_{\mathrm{f}} H_{\mathrm{m}}^{\circ}(1)$, Its Structure and Stability. Because of its good performance, the G3 technique was chosen to estimate the enthalpies of formation. Since 1 is formed by two adamantane $\left(\mathrm{C}_{10} \mathrm{H}_{16}\right)$ moieties,

\begin{tabular}{|c|c|c|c|}
\hline Reference base $\left(\mathrm{B}_{\text {ref }}\right)$ & $G B\left(\mathrm{~B}_{\mathrm{ref}}\right)^{\mathrm{b})}$ & $K_{p}$ & $G B(\mathbf{1})^{\mathrm{c})}$ \\
\hline $\mathrm{Et}_{2} \mathrm{~S}$ & 827.0 & 75.1 & 838.5 \\
\hline $\mathrm{CH}_{3} \mathrm{COCH}_{2} \mathrm{COCH}_{3}$ & 836.8 & 4.3 & 840.7 \\
\hline Pyrazine & 847.0 & 0.7 & 846.0 \\
\hline Average & & & $841.7 \pm 6.3^{d)}$ \\
\hline
\end{tabular}
we first examined its enthalpy of formation as well as that of cyclohexane, $c-\mathrm{C}_{6} \mathrm{H}_{12}$, a formal building block of adamantane. The effect of successive methyl substitutions on ethylene also was studied. The results are summarized in Table 3. In all cases,

Table 2. Experimental determination of $G B(\mathbf{1})^{\mathrm{a})}$

a) All values in $\mathrm{kJ} \mathrm{mol}^{-1}$. b) Values from ref 33. c) Determined using eq 5 , see text. d) Twice the standard deviations. 
Table 3. Experimental and computed standard enthalpies of formation for relevant species in $\mathrm{kJ} \mathrm{mol}^{-1}$

\begin{tabular}{llll}
\hline Compound & $\left.\Delta_{\mathrm{f}} H_{\mathrm{m}}^{\circ}(\mathrm{MP} 2),(\delta)^{\mathrm{a}}\right)$ & $\Delta_{\mathrm{f}} H_{\mathrm{m}}^{\circ}(\mathrm{G} 3),(\delta)^{\mathrm{b})}$ & $\left.\Delta_{\mathrm{f}} H_{\mathrm{m}}^{\circ}(\exp )^{\mathrm{c}}\right)$ \\
\hline $\mathrm{CH}_{4}$ & & & -74.87 \\
$\mathrm{C}_{2} \mathrm{H}_{6}$ & & $-104.6(0.3)$ & $-84.24 \pm 0.87$ \\
$\mathrm{C}_{3} \mathrm{H}_{8}$ & $-105.4(1.2)$ & $-133.9(-1.0)$ & $-104.3 \pm 0.8$ \\
$i-\mathrm{C}_{4} \mathrm{H}_{10}$ & $-136.1(1.2)$ & $-122.0(-1.6)$ & $-123.9 \pm 3.4$ \\
$c-\mathrm{C}_{6} \mathrm{H}_{12}$ & $-123.9(0.3)$ & -176.5 & $-177.8 \pm 7.9$ \\
$\left(\left(\mathrm{CH}_{3}\right)_{2} \mathrm{C}(\mathrm{H})\right)_{2}$ & & $-145.5(10.8)$ & $\left.-134.6 \pm 4.8^{\mathrm{f}}\right)$ \\
$\mathrm{C}_{10} \mathrm{H}_{16}$ & $-151.4(16.7)$ & $\left.-148.5(13.9)^{\mathrm{d}}\right)$ & $52.4 \pm 0.5$ \\
$\mathrm{C}_{2} \mathrm{H}_{4}$ & & & $20.4 \pm 0.1$ \\
$\mathrm{CH}_{3} \mathrm{C}(\mathrm{H})=\mathrm{CH}_{2}$ & $19.8(0.5)$ & $20.5(-0.1)$ & $-17.9 \pm 1.1$ \\
$\left(\mathrm{CH}_{3}\right)_{2} \mathrm{C}=\mathrm{CH}_{2}$ & $-16.6(-1.3)$ & $-15.8(-2.1)$ & $-41.3 \pm 0.9$ \\
$\left(\mathrm{CH}_{3}\right)_{2} \mathrm{C}=\mathrm{C}_{2}(\mathrm{H}) \mathrm{CH}$ & $-39.6(-1.7)$ & $-69.4 \pm 1.0$ \\
$\left(\mathrm{CH}_{3}\right)_{2} \mathrm{C}=\mathrm{C}_{3}\left(\mathrm{CH}_{3}\right)_{2}$ & $-41.4(0.1)$ & $-62.3(-7.1)$ & $\mathrm{NA}$ \\
$c-\mathrm{C}_{6} \mathrm{H}_{10}=\mathrm{CH}_{2}$ & $-65.4(-4.0)$ & -33.1 & $\mathrm{NA}$ \\
$\mathrm{C}_{10} \mathrm{H}_{14}=\mathrm{CH} \mathrm{CH}_{2}$ & -32.2 & -55.6 & $\mathrm{NA}$ \\
$c-\mathrm{C}_{6} \mathrm{H}_{10}=c-\mathrm{C}_{6} \mathrm{H}_{10}\left(C_{2 h}\right)$ & -96.2 & -100.7 & $\mathrm{NA}$ \\
$c-\mathrm{C}_{6} \mathrm{H}_{10}=c-\mathrm{C}_{6} \mathrm{H}_{10}\left(C_{2 v}\right)$ & -113.8 & -101.4 & $-138.0 \pm 6.8^{\mathrm{g})}$ \\
$\mathbf{1}(\mathrm{Ad}=\mathrm{Ad})$ & -114.1 & $-130.0(-10.0)^{\mathrm{g})}$ & $-242.6 \pm 7.9^{\mathrm{h})}$ \\
$2,2^{\prime}-\mathrm{Biadamantane}$ & $-183.3(45.3)$ & $-130.2(-7.8)^{\mathrm{e})}$ & \\
\hline
\end{tabular}

a) $\delta=\Delta_{\mathrm{f}} H^{\circ}{ }_{\mathrm{m}}(\exp )-\Delta_{\mathrm{f}} H_{\mathrm{m}}^{\circ}(\mathrm{calc})$. b) From ref 38 unless stated otherwise. c) Experimental. d) From reaction (6). e) From reaction (9). f) Average of the values given in refs 38 and 39. g) From reaction (7).

h) From refs 40 and 41 .

we used isodesmic ${ }^{37}$ bond separation processes such as reactions (6) and (7):

$$
\begin{aligned}
& \mathrm{C}_{10} \mathrm{H}_{16}+14 \mathrm{CH}_{4} \rightarrow 12 \mathrm{C}_{2} \mathrm{H}_{6} \\
& \mathbf{1}+30 \mathrm{CH}_{4} \rightarrow \mathrm{C}_{2} \mathrm{H}_{4}+24 \mathrm{C}_{2} \mathrm{H}_{6}
\end{aligned}
$$

We also applied homodesmotic reactions ${ }^{37}(8)$ and (9) to adamantane and $\mathbf{1}$ :

$$
\begin{aligned}
& \mathrm{C}_{10} \mathrm{H}_{16}+12 \mathrm{C}_{2} \mathrm{H}_{6} \rightarrow 6 \mathrm{C}_{3} \mathrm{H}_{8}+4 i-\mathrm{C}_{4} \mathrm{H}_{10} \\
& \mathbf{1}+28 \mathrm{C}_{2} \mathrm{H}_{6} \rightarrow \mathrm{C}_{2} \mathrm{H}_{4}+14 \mathrm{C}_{3} \mathrm{H}_{8}+8 i-\mathrm{C}_{4} \mathrm{H}_{10}
\end{aligned}
$$

As a simple example we can calculate the standard enthalpy of formation of $\mathbf{1}$. The experimental value is known but here we use eq 9 as if it was not.

$$
\begin{aligned}
& \Delta_{\mathrm{r}} H^{\circ}{ }_{\mathrm{m}}(\text { reaction 9) } \\
&=\Delta_{\mathrm{f}} H^{\circ}{ }_{\mathrm{m}}\left(\mathrm{C}_{2} \mathrm{H}_{4}\right)+14 \times \Delta_{\mathrm{f}} H^{\circ}{ }_{\mathrm{m}}\left(\mathrm{C}_{3} \mathrm{H}_{8}\right)+8 \\
& \times \Delta_{\mathrm{f}} H^{\circ}{ }_{\mathrm{m}}\left(i-\mathrm{C}_{4} \mathrm{H}_{10}\right)-26 \\
& \times \Delta_{\mathrm{f}} H^{\circ}{ }_{\mathrm{m}}\left(\mathrm{C}_{2} \mathrm{H}_{6}\right)-\Delta_{\mathrm{f}} H^{\circ}{ }_{\mathrm{m}}(\mathbf{1}) .
\end{aligned}
$$

Now, we can obtain, for instance, $\Delta_{\mathrm{r}} H^{\circ}{ }_{\mathrm{m}}$ (reaction 9) at the G3 level since all the values of $\Delta_{\mathrm{f}} H^{\circ} \mathrm{m}$ involved are available. We call it $\Delta_{\mathrm{r}} H^{\circ}$ (reaction $\left.9, \mathrm{G} 3\right)$. We also know all the experimental values of $\Delta_{\mathrm{f}} H^{\circ}{ }_{\mathrm{m}}\left(\mathrm{C}_{2} \mathrm{H}_{4}\right), \quad \Delta_{\mathrm{f}} H^{\circ}{ }_{\mathrm{m}}\left(\mathrm{C}_{3} \mathrm{H}_{8}\right), \quad \Delta_{\mathrm{f}} H^{\circ}{ }_{\mathrm{m}}(i-$ $\left.\mathrm{C}_{4} \mathrm{H}_{10}\right)$ and $\Delta_{\mathrm{f}} H_{\mathrm{m}}^{\circ}\left(\mathrm{C}_{2} \mathrm{H}_{6}\right)$. Thus, combining $\Delta_{\mathrm{r}} H^{\circ}$ m (reaction 9, G3) and the stoechiometric numbers of the experimental enthalpies we obtain the value of $\Delta_{\mathrm{f}} H^{\circ}{ }_{\mathrm{m}}(\mathbf{1})$ given in Table 3.

Table 3 presents the experimental and computational data [at both the G3 and MP2/6-311+G(d,p) levels]. $\delta$ is the difference between the experimental and computational standard enthalpies of formation. The $\Delta_{\mathrm{f}} H^{\circ}{ }_{\mathrm{m}}(\exp )$ value for $2,2^{\prime}$-biadamantane was determined by combining the standard enthalpy of formation of $1,1^{\prime}$-biadamantane, $-242.6 \pm 7.9 \mathrm{~kJ} \mathrm{~mol}^{-1}$, ${ }^{40}$ with the enthalpy of isomerization $1,1^{\prime}$-biadamantane $\rightarrow 2,2^{\prime}$-biadamantane, $4.64 \pm 0.50 \mathrm{~kJ} \mathrm{~mol}^{-1} .41$
This table shows that most absolute values of $\delta$ for MP2 and G3 calculated values are quite similar, with two significant exceptions, adamantane and 1, possibly because G3 better accounts for the internal strain and other structural effects in the adamantyl systems. Homodesmotic reactions (8) and (9) do not perform significantly better than the isodesmic reactions (6) and (7).

There is also a source of uncertainty that increases with the size of the molecules. Consider the cases of $\mathbf{1}$ and adamantane. The coefficients for the ancillary species $\mathrm{CH}_{4}, \mathrm{C}_{2} \mathrm{H}_{6}$, and $i$ $\mathrm{C}_{4} \mathrm{H}_{10}$ in equations such as (6), (7), (8), and (9) are large. Thus, even if the experimental errors on the molar heats of formation of these species are small, their final contribution to the overall computed enthalpies might be significant. We summarize in Table 4 the experimental and computed thermochemistry of some reactions that shed light on properties of this family of compounds.

Thermodynamics of Reactions, NBO and AIM Analyses. At variance with reactions (6)-(9), the agreement between the experimental and computed enthalpies for reaction (10) is very good and tends to confirm that the larger differences between the experimental and computed values in reactions (6)-(9) originate in the cage structures.

Reactions (11) and (12) are important as they correspond to the hydrogenation of the double bonds in $\mathbf{1}$ and in tetramethylethylene to yield 2,2'-biadamantane and 2,3-dimethylbutane, respectively. All the experimental values required are available and both enthalpies differ by only $3.8 \mathrm{~kJ} \mathrm{~mol}^{-1}$, well within the limits of experimental uncertainty. This strongly suggests that hyperconjugation effects and internal repulsions are very similar in the couples $1 / 2,2^{\prime}$-biadamantane and tetramethylethylene/2,3-dimethylbutane. The agreement between the experimental and G3 enthalpies for reaction (12) is also good. 
Table 4. Thermodynamics of selected reactions (in $\mathrm{kJ} \mathrm{mol}^{-1}$ )

\begin{tabular}{|c|c|c|c|}
\hline Reaction & $\Delta_{\mathrm{r}} H_{\mathrm{m}}^{\circ}(\exp )$ & $\Delta_{\mathrm{r}} H_{\mathrm{m}}^{\circ}(\mathrm{G} 3)$ & $\Delta_{\mathrm{r}} H_{\mathrm{m}}^{\circ}(\mathrm{MP} 2)$ \\
\hline (6) $\mathrm{C}_{10} \mathrm{H}_{16}+14 \mathrm{CH}_{4} \rightarrow 12 \mathrm{C}_{2} \mathrm{H}_{6}$ & 174.1 & 182.8 & 190.7 \\
\hline (7) $\mathrm{I}+30 \mathrm{CH}_{4} \rightarrow 24 \mathrm{C}_{2} \mathrm{H}_{6}+\mathrm{C}_{2} \mathrm{H}_{4}$ & 415.1 & 431.5 & 464 \\
\hline (8) $\mathrm{C}_{10} \mathrm{H}_{16}+12 \mathrm{C}_{2} \mathrm{H}_{6} \rightarrow 6 \mathrm{C}_{3} \mathrm{H}_{8}+4 i-\mathrm{C}_{4} \mathrm{H}_{10}$ & -19.9 & -9.1 & -14.8 \\
\hline (9) $\mathrm{1}+28 \mathrm{C}_{2} \mathrm{H}_{6} \rightarrow \mathrm{C}_{2} \mathrm{H}_{4}+14 \mathrm{C}_{3} \mathrm{H}_{8}+8 i-\mathrm{C}_{4} \mathrm{H}_{10}$ & 9.7 & 23 & 29.2 \\
\hline (10) $c-\mathrm{C}_{6} \mathrm{H}_{12}+6 \mathrm{CH}_{4} \rightarrow 6 \mathrm{C}_{2} \mathrm{H}_{6}$ & 67.6 & 66.8 & 68.7 \\
\hline (11) $1+\mathrm{H}_{2} \rightarrow 2,2^{\prime}$-biadamantane & -104.6 & & \\
\hline (12) $\left(\mathrm{CH}_{3}\right)_{2} \mathrm{C}=\mathrm{C}\left(\mathrm{CH}_{3}\right)_{2}+\mathrm{H}_{2} \rightarrow\left(\left(\mathrm{CH}_{3}\right)_{2} \mathrm{C}(\mathrm{H})\right)_{2}$ & -108.4 & -112.8 & \\
\hline (13) $c-\mathrm{C}_{6} \mathrm{H}_{10}=\mathrm{CH}_{2}+\mathrm{C}_{10} \mathrm{H}_{16} \rightarrow \mathrm{C}_{10} \mathrm{H}_{14}=\mathrm{CH}_{2}+c-\mathrm{C}_{6} \mathrm{H}_{12}$ & NA & -0.7 & \\
\hline (14) $c-\mathrm{C}_{6} \mathrm{H}_{10}=c-\mathrm{C}_{6} \mathrm{H}_{10}\left(C_{2 h}\right)+2 \mathrm{C}_{10} \mathrm{H}_{16} \rightarrow \mathbf{1}+2 c-\mathrm{C}_{6} \mathrm{H}_{12}$ & NA & -7.1 & -14.2 \\
\hline (15) $c-\mathrm{C}_{6} \mathrm{H}_{10}=c-\mathrm{C}_{6} \mathrm{H}_{10}\left(C_{2 v}\right)+2 \mathrm{C}_{10} \mathrm{H}_{16} \rightarrow \mathbf{1}+2 c-\mathrm{C}_{6} \mathrm{H}_{12}$ & NA & -6.7 & -14.5 \\
\hline (16) $2 \mathrm{C}_{10} \mathrm{H}_{16}+\left(\mathrm{CH}_{3}\right)_{2} \mathrm{C}=\mathrm{C}\left(\mathrm{CH}_{3}\right)_{2} \rightarrow \mathbf{1}+2 \mathrm{C}_{3} \mathrm{H}_{8}$ & -7.8 & -10.7 & -25.3 \\
\hline (17) $2,2^{\prime}$-biadamantane $+\left(\mathrm{CH}_{3}\right)_{2} \mathrm{C}=\mathrm{C}\left(\mathrm{CH}_{3}\right)_{2} \rightarrow \mathbf{1}+\left(\left(\mathrm{CH}_{3}\right)_{2} \mathrm{C}(\mathrm{H})\right)_{2}$ & -8.4 & & \\
\hline (18) $2 c-\mathrm{C}_{6} \mathrm{H}_{12}+\mathrm{C}_{2} \mathrm{Me}_{4} \rightarrow c-\mathrm{C}_{6} \mathrm{H}_{10}=c-\mathrm{C}_{6} \mathrm{H}_{10}\left(C_{2 h}\right)+2 \mathrm{C}_{3} \mathrm{H}_{8}$ & NA & -3.8 & -10.8 \\
\hline (19) $2 c-\mathrm{C}_{6} \mathrm{H}_{12}+\mathrm{C}_{2} \mathrm{Me}_{4} \rightarrow c-\mathrm{C}_{6} \mathrm{H}_{10}=c-\mathrm{C}_{6} \mathrm{H}_{10}\left(C_{2 v}\right)+2 \mathrm{C}_{3} \mathrm{H}_{8}$ & NA & -4.2 & -11.1 \\
\hline
\end{tabular}

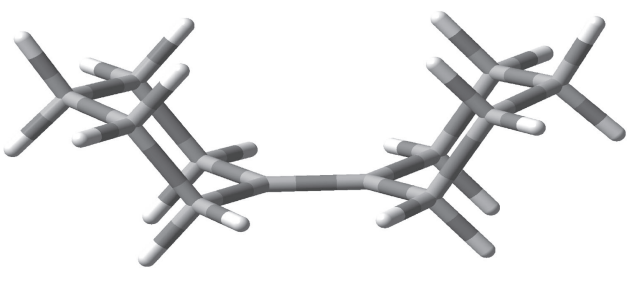

Figure 2. $C_{2 v}$ structure.

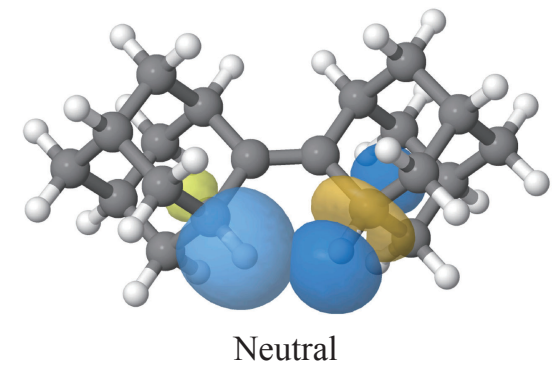

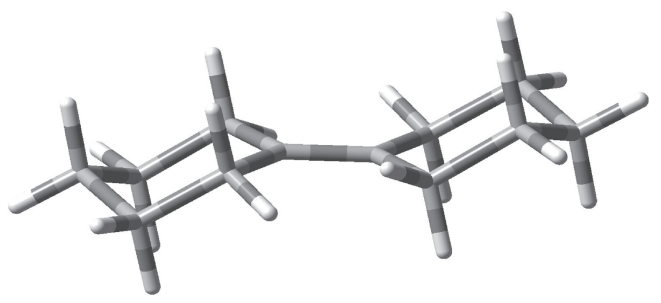

Figure 3. $C_{2 h}$ structure.

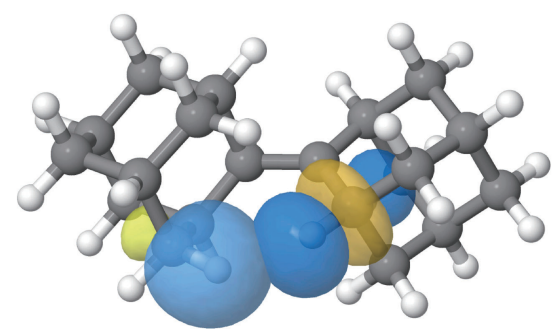

Protonated

Figure 4. Relevant $\sigma$ orbitals involved in the NBO study.

In tetramethylethylene and 2,3-dimethylbutane there are two different contributions to the internal strain of these compounds, essentially two cis interactions in the former and two gauche(1-4) interactions in the latter case (corresponding to 11.4 and $9.6 \mathrm{~kJ} \mathrm{~mol}^{-1}$, respectively). ${ }^{30,42}$ These effects essentially compensate each other in the hydrogenation process.

Reaction (13) allows comparison of the relative stabilities of the ethylenic bonds between a methylene group and cyclohexane or adamantane. At the G3 level, they differ by -0.7 $\mathrm{kJ} \mathrm{mol}^{-1}$, indicating essentially the same stability of these bonds and do not show any special effect from the cage structure.

Cyclohexylidenecyclohexane, $c-\mathrm{C}_{6} \mathrm{H}_{10}=c-\mathrm{C}_{6} \mathrm{H}_{10}$, can adopt two different conformations, with $C_{2 h}$ and $C_{2 v}$ symmetries, respectively (Figures 2 and 3). Table 4 shows that their stabilities are extremely close, the latter being more stable (reactions 14 and 15) as indicated by their G3-computed $\Delta_{\mathrm{f}} H_{\mathrm{m}}^{\circ}$ values (Table 3 ). The shortest inter-ring $\mathrm{C}-\mathrm{H} \cdots \mathrm{H}-\mathrm{C}$ distances in these species, respectively 1.894 and $1.895 \AA$ for the $C_{2 h}$ and $C_{2 v}$ conformers are slightly longer than in $1,1.851 \AA$ (all values at the MP2/6-311+G(d,p) level). These distances are shorter than the corresponding van der Waals distance sum.
The short $\mathrm{H}$...H distances in $\mathbf{1}$ prompted "Atoms in Molecules" (AIM) studies. ${ }^{43}$ In Figure 4 the relevant $\sigma$ orbitals pertaining to these interactions in both $\mathbf{1}$ and $\mathbf{1 H}^{+}$are shown. The topological analysis of the electron density allows location of the position of critical points where the gradient vanishes. The critical points, especially those with $(3,-1)$ signature that are called bond critical points, characterized the interactions ${ }^{44}$ based on the value of the electron density and its second derivative, Laplacian. Indeed, Figure 5 shows that the corresponding graphs have bond critical points (green dots) between each pair of the two neighboring $\mathrm{C}-\mathrm{H}$ groups. The values of the electron density $\rho(0.017 \mathrm{au})$ and its Laplacian $(0.057 \mathrm{au})$ at the bond critical points are in the range of closed shell interactions which are typical of weak interactions. The value reported is between the two closest $\mathrm{H}$ atoms (H6-H19, 1.836 $\mathrm{A}$ ). The interaction between the H19-H12 (2.346 $)$ in $1 \mathrm{H}^{+}$does not show a charge transfer above the threshold of the Natural Bond Orbital Theory (NBO) program $\left(0.5 \mathrm{kcal} \mathrm{mol}^{-1}\right)$.

The second-order perturbation analysis within the $\mathrm{NBO}^{44}$ methodology shows four degenerate charge-transfer interactions between the $\sigma \mathrm{C}-\mathrm{H}$ bond of one of the adamantyl subunits 
towards the $\sigma^{*} \mathrm{C}-\mathrm{H}$ of the other adamantyl subunit. Each interaction has a value of $2.2 \mathrm{~kJ} \mathrm{~mol}^{-1}$. The interaction between of two neighboring $\mathrm{CH}$ is associated to an overall destabilization effect on the molecule but a local stabilization using some partition methods. ${ }^{45}$ We present in Figure 6 the critical points of $1 \mathrm{H}^{+}$.

The intramolecular $\mathrm{H}-\mathrm{H}$ interactions have been discussed in the literature. The seminal work of Martín-Pendás and co-workers shows that the presence of a bond critical point corresponds to a local stabilization of the atoms involved while it could correspond to an overall destabilization of the system. $^{46}$

The G3-computed standard enthalpy changes for reactions (14) and (15) are slightly negative (ca. $-7 \mathrm{~kJ} \mathrm{~mol}^{-1}$ ). This effect is well within the range of uncertainties of the computational and experimental methods.

The proton basicity of $\mathbf{1}$. The results of our study of the neutral and protonated forms of $\mathbf{1}$ and a series of simple ethylenic hydrocarbons using the same computational techniques as above are summarized in Table 5 .

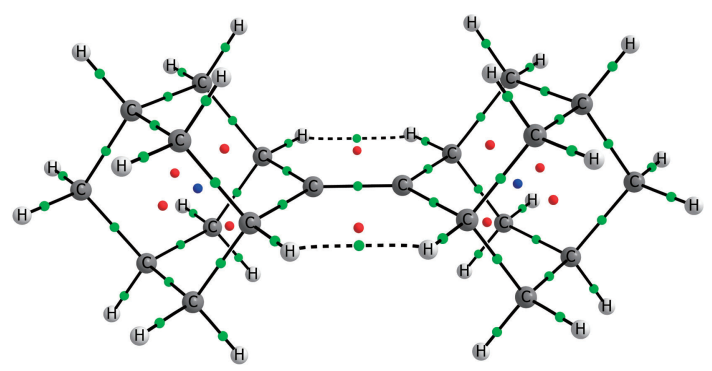

Figure 5. Critical points in neutral adamantylideneadamantane. Green, red, and blue dots indicate the location of the bond, ring and cage critical points, respectively. The lines connecting the atomic positions indicate the bond paths.

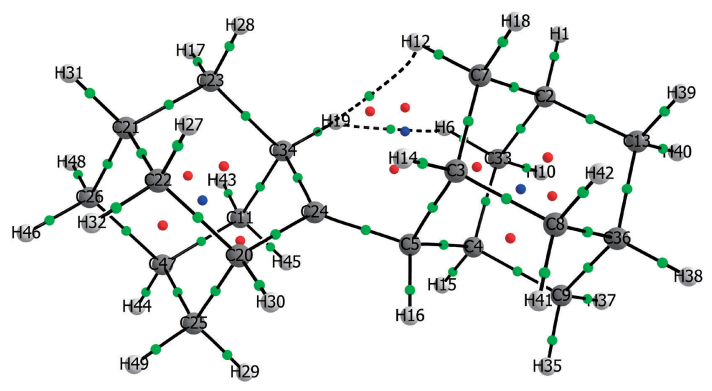

Figure 6. Critical points in protonated adamantylideneadamantane.
Our prior experimental determination of the stability of a variety of carbenium ions in the gas phase $\mathrm{s}^{47,48}$ established a ranking of thermodynamic stabilities based on the chloride anion exchange process (27):

$$
\mathrm{R}_{1}{ }^{+}+\mathrm{R}_{2}-\mathrm{Cl} \rightarrow \mathrm{R}_{1}-\mathrm{Cl}+\mathrm{R}_{2}{ }^{+} \quad \Delta_{\mathrm{r}} G_{\mathrm{m}}^{\circ}(27)
$$

The reference species $\mathrm{R}_{1}{ }^{+}$and $\mathrm{R}_{1}-\mathrm{Cl}$ were 1 -adamantyl cation and 1-chloroadamantane, respectively. Quite recently, a comprehensive study of the stabilities of carbenium ions in solution has been presented. ${ }^{49}$

Here, we are dealing with hydride exchanges. The present work allows comparison of the stabilities of 2-substituted adamantyl cations through reaction (28):

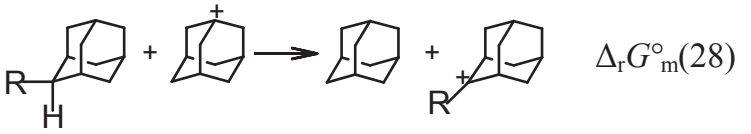

The standard Gibbs energy and enthalpy values for reaction (28), $\Delta_{\mathrm{r}} G_{\mathrm{m}}^{\circ}(28)$ and $\Delta_{\mathrm{r}} H^{\circ}{ }_{\mathrm{m}}(28)$ for different substituents are summarized in Table 6 .

Consideration of polarizability parameters ${ }^{50}$ or substituents seems appropriate. We present in Table 6 Taft's polarizability parameters $\sigma_{\alpha}$ for these substituents. ${ }^{50}$ It is interesting that the values for $\mathrm{R}=$ tert-Bu and 2-adamantyl are large and rather close. tert-Bu is the less bulky tertiary substituent and 2adamantyl is a very large secondary substituent. As it is often the case, the stability of these ions depends on the polarizability of the substituents and here, the polarizability of the 2adamantyl fragment is larger than that of tert-Bu. This notwithstanding, the values of $\Delta_{\mathrm{r}} G_{\mathrm{m}}^{\circ}(28)$ for the latter two substituents are very close and the absolute value for $\mathrm{R}=n e o$-Pentyl is close to that for $\mathrm{R}=\mathrm{Me}$. The second fundamental factor is the stability of $\mathrm{R}^{+}$, the charge being spread over the two moieties. Their standard enthalpies are also presented in Table 6. Clearly, the values of $\Delta_{\mathrm{r}} G_{\mathrm{m}}^{\circ}(28)$ reflect both contributions.

As regards structural effects on the stability of $1 \mathrm{H}^{+}$, Figure 6 presents an AIM analysis of this ion. In this case, the bond paths linking the two adamantyl units connect a hydrogen atom alpha to the carbocationic atom with two hydrogen atoms in two $\mathrm{CH}_{2}$ groups of the other adamantyl unit. The largest values of the electron density ( 0.016 and $0.008 \mathrm{au}$ ) and its Laplacian $(0.051$ and $0.030 \mathrm{au})$ at the bond critical points respectively correspond to the shortest and longest $\mathrm{H} \cdots \mathrm{H}$ distances. In the first case, the values are similar to those found in neutral 1. For the longer contact, they are about half as large. In the case of the shortest contact, the NBO analysis shows a charge transfer between the $\sigma \mathrm{C}-\mathrm{H}$ bond in the neutral adamantyl unit towards

Table 5. Experimental and computed standard gibbs energy changes for the protonation of selected ethylenic hydrocarbons ${ }^{\text {a) }}$

\begin{tabular}{|c|c|c|c|}
\hline Reaction & $\Delta_{\mathrm{r}} G_{\mathrm{m}}^{\circ}(\mathrm{MP} 2)^{\mathrm{b})}$ & $\Delta_{\mathrm{r}} G_{\mathrm{m}}^{\circ}(\mathrm{G} 3)^{\mathrm{b})}$ & Exp. $^{\text {c) }}$ \\
\hline (20) $\mathrm{C}_{2} \mathrm{H}_{4}+\mathrm{H}^{+} \rightarrow \mathrm{C}_{2} \mathrm{H}_{5}^{+}$ & -650.2 & -651.4 & -651 \\
\hline (21) $\mathrm{CH}_{3} \mathrm{C}(\mathrm{H})=\mathrm{CH}_{2}+\mathrm{H}^{+} \rightarrow i-\mathrm{C}_{3} \mathrm{H}_{7}^{+}$ & -710 & -715.5 & -722.6 \\
\hline (22) $\left(\mathrm{CH}_{3}\right)_{2} \mathrm{C}=\mathrm{CH}_{2}+\mathrm{H}^{+} \rightarrow t-\mathrm{C}_{4} \mathrm{H}_{9}{ }^{+}$ & -770.7 & -779.5 & -775.7 \\
\hline (23) $\left.\left(\mathrm{CH}_{3}\right)_{2} \mathrm{C}=\mathrm{C}(\mathrm{H}) \mathrm{CH}_{3}+\mathrm{H}^{+} \rightarrow\left[\left(\mathrm{CH}_{3}\right)_{2} \mathrm{CCH}_{2} \mathrm{CH}_{3}\right)\right]^{+}$ & -769.9 & -780.3 & -779.9 \\
\hline (24) $\left.\left(\mathrm{CH}_{3}\right)_{2} \mathrm{C}=\mathrm{C}\left(\mathrm{CH}_{3}\right)_{2}+\mathrm{H}^{+} \rightarrow\left[\left(\mathrm{CH}_{3}\right)_{2} \mathrm{C}-\mathrm{C}\left(\mathrm{CH}_{3}\right)_{2} \mathrm{H}\right)\right]^{+}$ & -784.1 & -792.5 & -783.2 \\
\hline (25) $\mathrm{Ad}=\mathrm{CH}_{2}+\mathrm{H}^{+} \rightarrow \mathrm{AdCH}_{3}{ }^{+}$ & -817.6 & -829.3 & NA \\
\hline (26) $\mathrm{Ad}=\mathrm{Ad}+\mathrm{H}^{+} \rightarrow(\operatorname{AdAdH})^{+}$ & -824.2 & $-838.1^{\mathrm{b}), \mathrm{d})}$ & -842.0 \\
\hline
\end{tabular}

a) All values in $\mathrm{kJ} \mathrm{mol}^{-1}$. b) This work. c) From ref 33 unless stated otherwise. d) See text. 
Table 6. Structural effects on the thermodynamics of reaction $(28)^{\mathrm{a})}$

\begin{tabular}{llllc}
\hline $\mathrm{R}$ & $\Delta_{\mathrm{r}}{H^{\circ}}_{\mathrm{m}}^{\mathrm{a})}$ & $\Delta_{\mathrm{r}} G_{\mathrm{m}}^{\mathrm{o}}{ }^{\mathrm{a})}$ & $\sigma_{\alpha}{ }^{\mathrm{b})}$ & $\Delta_{\mathrm{f}} H^{\circ}{ }_{\mathrm{m}}\left(\mathrm{R}^{+}\right)^{\mathrm{h})}$ \\
\hline $\mathrm{Me}$ & $-12.2^{\mathrm{c})}$ & $-12.3^{\mathrm{c})}$ & -0.35 & 1095 \\
$t$ - $\mathrm{Bu}$ & $-46.2^{\mathrm{d}), \mathrm{e})}$ & $-48.9^{\mathrm{c}), \mathrm{d})}$ & -0.75 & 677.8 \\
neo-Pent & $-16.5^{\mathrm{c})}$ & $-13.8^{\mathrm{c})}$ & -0.67 & 789.9 \\
2-Ad & $-48.8^{\mathrm{d}), \mathrm{e})}$ & $-50.4^{\mathrm{f})}$ & $-0.95^{\mathrm{g})}$ & 717.6 \\
\hline
\end{tabular}

a) All values in $\mathrm{kJ} \mathrm{mol}^{-1}$. b) From ref 47. c) Computational (G3 level). d) Experimental, based on data from ref 33. e) Entropy correction is computational. f) Experimental, this work. g) Value for 1-adamantyl. No value for 2-adamantyl is available. h) Refs 48 and 49.

the $\sigma^{*} \mathrm{C}-\mathrm{H}$ in the carbocationic moiety and the corresponding stabilization is calculated by the AIM program at $5.7 \mathrm{~kJ} \mathrm{~mol}^{-1}$.

Ionization energy of $\mathbf{1}$. As indicated earlier, the experimental vertical ionization potential of $\mathbf{1}$ is $7.84 \mathrm{eV} \cdot{ }^{12,15}$ We have estimated both its adiabatic and vertical ionization energies. The adiabatic ionization energy was computed as the change in standard energy for reaction (29):

$$
\mathbf{1}(\mathrm{g}) \rightarrow \mathbf{1}^{+\cdot}(\mathrm{g})+\mathrm{e}^{-}
$$

We have used the MP2/6-311+G(d,p). Values for the fully optimized species 1 and $\mathbf{1}^{+\cdot}$ and taken an energy of $3 / 2 R T$ for the free electron, corresponding to the ion convention. ${ }^{51}$ As is typical, the calculated adiabatic value is $7.64 \mathrm{eV}, 0.20 \mathrm{eV}$ (ca. $19 \mathrm{~kJ} \mathrm{~mol}^{-1}$ ) lower than the vertical value. The vertical ionization energy is based on reaction (29) with the geometry of $\mathbf{1}^{+\bullet}$ being the same as that of $1 .^{51}$ Our result, $8.11 \mathrm{eV}$, was $0.27 \mathrm{eV}$ higher than the experimental value.

The outer valence Green's function approach $(\mathrm{OVGF})^{52}$ was also tried. Although accurate values require very large basis sets ${ }^{53}$ we used the same $6-311+\mathrm{G}(\mathrm{d}, \mathrm{p})$ basis set due to the size of 1 . The resulting vertical ionization energy, $7.68 \mathrm{eV}$, was $0.16 \mathrm{eV}$ lower than the experimental value. In short, while both these computational approaches are of a modest level, they independently agree with the low ionization energies of 1 .

\section{Conclusion}

The standard enthalpy of formation of $\mathbf{1}$ together with the energetic results (experimental and computational) of a series of reference reactions as well as the AIM and NBO studies of this compound leads to the conclusion that the apparent crowding of this molecule does not entail a significant loss of stability. Rather high $G B(\mathbf{1})$ value seems to be mostly a consequence of large polarizability effects.

\section{Experimental and Computational}

Materials. Adamantylideneadamantane (1) was prepared according to Lenoir, ${ }^{54}$ whereby adamantanone was subjected to a standard McMurry reaction ${ }^{55}$ with $\mathrm{TiCl}_{4}$ and $\mathrm{Zn}$ in THF. The crude material was purified by chromatography on silica with $n$-hexane as eluent. The product was crystallized twice from methanol and dried in vacuo to give white crystals (mp 193$195^{\circ} \mathrm{C}$ ). This material was subject to two successive sublimations. The mass spectra did not show any impurities in significant amounts.
FT-ICR Experiments. The foreline and the glass tube containing the sample of $\mathbf{1}$ were heated to ca. $80^{\circ}$. No impurities were evident.

Computational Methods. Geometry optimizations and NBO calculations were carried out using Gaussian ${ }^{56}$ Atoms in Molecules (AIM) calculations were performed with the AIMII program. ${ }^{57}$ The electron densities of complexes have been analyzed using the AIM methodology employing the AIMll program. The topological analysis of the electron density produces the molecular graph of each complex. This graph identifies the location of electron density features of interest, including the electron density maxima associated with the various nuclei, and saddle points which correspond to bond critical points (BCPs). The zero gradient line which connects a $\mathrm{BCP}$ with two nuclei is the bond path.

This work was supported by Projects CTQ2006-10178/ BQU, CTQ2009-13652, and CTQ200913129C0202 from the Spanish MICINN Projects. Also, from Comunidad Autónoma de Madrid (Project MADRISOLAR2, ref S2009/ PPQ1533) and by institutional research funding IUT2014(TLOKT140141) of the Estonian Ministry of Education and Research and by the Estonian Centre of Excellence HIGHTECHMAT(SLOKT117T). Thanks are given to the staff of SGAI-CSIC for technical support.

\section{Supporting Information}

Enthalpy and free energies of all species calculated at the G3, G3(MP2), and MP2/6-311+G(d,p). This material is available on http://dx.doi.org/10.1246/bcsj.20160026.

\section{References}

1 P. R. Schreiner, L. V. Chernish, P. A. Gunchenko, E. Y. Tikhonchuk, H. Hausmann, M. Serafin, S. Schlecht, J. E. P. Dahl, R. M. K. Carlson, A. A. Fokin, Nature 2011, 477, 308.

2 P. R. Schreiner, N. A. Fokina, B. A. Tkachenko, H. Hausmann, M. Serafin, J. E. P. Dahl, S. Liu, R. M. K. Carlson, A. A. Fokin, J. Org. Chem. 2006, 71, 6709.

3 S. Inomata, S. Matsuoka, S. Sakai, H. Tajima, T. Ishizone, Macromolecules 2012, 45, 4184.

4 A. Guerrero, R. Herrero, E. Quintanilla, J. Z. Dávalos, J.-L. M. Abboud, P. B. Coto, D. Lenoir, ChemPhysChem 2010, 11, 713.

5 R. Rathore, S. V. Lindeman, C.-J. Zhu, T. Mori, P. v. R. Schleyer, J. K. Kochi, J. Org. Chem. 2002, 67, 5106.

6 S. C. Swen-Walstra, G. J. Visser, J. Chem. Soc. D 1971, 82.

7 P. v. R. Schleyer, J. E. Williams, Jr., K. R. Blanchard, J. Am. Chem. Soc. 1970, 92, 2377.

8 Computed at the MP2/6-311+G(d,p) level, this work

9 S. F. Nelsen, C. R. Kessel, J. Am. Chem. Soc. 1979, 101, 2503.

10 S. F. Nelsen, M. F. Teasley, D. L. Kapp, C. R. Kessel, L. A. Grezzo, J. Am. Chem. Soc. 1984, 106, 791.

11 T. Clark, M. F. Teasley, S. F. Nelsen, H. Wynberg, J. Am. Chem. Soc. 1987, 109, 5719.

12 R. Akaba, H. Sakuragi, K. Tokumaru, Tetrahedron Lett. 1984, 25, 665

13 E. Bosch, J. K. Kochi, J. Am. Chem. Soc. 1996, 118, 1319.

14 E. Bosch, J. K. Kochi, J. Chem. Soc., Chem. Commun. 1993, 667. 
15 P. D. Mollere, K. N. Houk, D. S. Bomse, T. H. Morton, J. Am. Chem. Soc. 1976, 98, 4732.

16 D. Lenoir, P. J. Smith, J. F. Liebman, in Strained Hydrocarbons, ed. by H. Dodziuk, Wiley-VCH, Weinheim, 2009, Chap. 3, pp. 103-122.

17 D. Lenoir, R. M. Frank, F. Cordt, A. Gieren, V. Lamm, Chem. Ber. 1980, 113, 739.

18 O. Kekišev, I. Kaljurand, L. Toom, D. Lenoir, P. Burk, J. Järv, J. Phys. Org. Chem. 2015, $28,447$.

19 E. P. L. Hunter, S. G. Lias, J. Phys. Chem. Ref. Data 1998, $27,413$.

20 A. F. Lago, P. Jimenez, R. Herrero, J. Z. Dávalos, J.-L. M. Abboud, J. Phys. Chem. A 2008, 112, 3201.

21 M. Colomina, P. Jiménez, C. Turrión, J. A. Fernández, C. Monzón, An. Quim. 1980, 76, 245.

22 M. Colomina, P. Jiménez, C. Turrión, J. Chem. Thermodyn. 1982, 14, 779.

23 P. Jiménez, M. V. Roux, J. Z. Dávalos, M. A. MartínLuengo, J.-L. M. Abboud, J. Chem. Thermodyn. 1997, 29, 1281.

24 J.-L. M. Abboud, B. Németh, J.-C. Guillemin, P. Burk, A. Adamson, E. R. Nerut, Chem.-Eur. J. 2012, 18, 3981.

25 A. Guerrero, R. Herrero, E. Quintanilla, J. Z. Dávalos, J.-L. M. Abboud, P. B. Coto, D. Lenoir, ChemPhysChem 2010, 11, 713.

26 F. H. Laukien, M. Allemann, P. Bischofberger, P. Grossmann, P. Kellerhals, P. Kofel, in Fourier Transform Mass Spectrometry. Evolution, Innovation and Applications, in ACS Symp. Ser., ed. by M. V. Buchanan, American Chemical Society, Washington, 1987, Vol. 359, Chap. 5. doi:10.1021/bk-19870359.ch005.

27 A. G. Marshall, C. L. Hendrickson, Int. J. Mass Spectrom. 2002, 215, 59.

28 J.-F. Gal, P.-C. Maria, E. D. Raczynska, J. Mass Spectrom. 2001, 36, 699.

29 J.-L. M. Abboud, R. Notario, in Energetics of Stable Molecules and Reactive Intermediates, in NATO Science Series, ed. by M. E. Minas da Piedade, Kluwer, Dordrecht, 1999, Vol. 535, p. 281. doi:10.1007/978-94-011-4671-5_13.

30 A. G. Marshall, C. L. Hendrickson, G. S. Jackson, Mass Spectrom. Rev. 1998, 17, 1.

31 G. Bouchoux, J. Y. Salpin, D. Leblanc, Int. J. Mass Spectrom. Ion Processes 1996, 153, 37.

32 G. Bouchoux, J. Y. Salpin, J. Am. Chem. Soc. 1996, 118, 6516.

33 S. G. Lias, J. E. Bartmess, Gas-Phase Ion Thermochemistry, in NIST Chemistry WebBook, NIST Standard Reference Database Number 69, P. J. Linstrom, W. G. Mallard. NIST, Gaithersburg, MD, 20899.

34 See, e.g., W. J. Hehre, A Guide to Molecular Mechanics and Quantum Chemical Calculations, Wavefunction Inc., Irvine (CA), 2003.

35 L. A. Curtiss, K. Raghavachari, P. C. Redfern, V. Rassolov, J. A. Pople, J. Chem. Phys. 1998, 109, 7764.

36 L. A. Curtiss, P. C. Redfern, K. Raghavachari, V. Rassolov, J. A. Pople, J. Chem. Phys. 1999, 110, 4703.

37 S. E. Wheeler, K. N. Houk, P. v. R. Schleyer, W. D. Allen, J. Am. Chem. Soc. 2009, 131, 2547.

38 H. Y. Afeefy, J. F. Liebman, S. E. Stein, Neutral Thermochemical Data. in NIST Chemistry WebBook, NIST Standard Reference Database Number 69, P. J. Linstrom, W. G. Mallard, NIST, Gaithersburg, MD, 20899, http://webbook.nist.gov.
39 A. B. Bazyleva, A. V. Blokhin, G. J. Kabo, M. B. Charapennikau, V. N. Emel'yanenko, S. P. Verevkin, V. Diky, J. Phys. Chem. B 2011, 115, 10064.

40 L. S. Karpushenkava, G. J. Kabo, A. B. Bazyleva, A. V. Blokhin, A. G. Kabo, D. H. Zaitsau, A. A. Pimerzin, V. S. Sarkisova, Thermochim. Acta 2007, 459, 104.

41 J. Slutsky, E. M. Engler, P. v. R. Schleyer, J. Chem. Soc. Chem. Comm. 1973, 685.

42 N. Cohen, S. W. Benson, Chem. Rev. 1993, 93, 2419 and references therein.

43 R. F. W. Bader, Atoms in Molecules: A Quantum Theory, in The International Series of Monographs of Chemistry, ed. by J. Halpen, M. L. H., Green, Clarendon Press, Oxford, 1990.

44 A. E. Reed, L. A. Curtiss, F. Weinhold, Chem. Rev. 1988, 88,899 .

45 I. Rozas, I. Alkorta, J. Elguero, J. Am. Chem. Soc. 2000 , $122,11154$.

46 A. M. Pendás, E. Francisco, M. A. Blanco, C. Gatti, Chem.-Eur. J. 2007, 13, 9362.

47 J.-L. M. Abboud, I. Alkorta, J. Z. Dávalos, P. Müller, E. Quintanilla, Adv. Phys. Org. Chem. 2002, 37, 57.

48 J.-L. M. Abboud, O. Castaño, E. W. Della, M. Herreros, P. Müller, R. Notario, J.-C. Rossier, J. Am. Chem. Soc. 1997, 119, 2262.

49 M. Horn, L. H. Schappele, G. Lang-Wittkowski, H. Mayr, A. R. Ofial, Chem.-Eur. J. 2013, 19, 249.

50 C. Hansch, A. Leo, R. W. Taft, Chem. Rev. 1991, 91, 165.

51 J. O. Hirschfelder, C. F. Curtiss, R. B. Bird, Molecular Theory of Gases and Liquids, John Wiley, New York, 1967, pp. 960 and 984.

52 See, e.g., A. Dhouib, M. Abderrabba, K. Essalah, V. Brites, M. Hochlaf, Int. J. Quantum Chem. 2012, 112, 2032.

53 See, e.g., W. Von Niessen, L. S. Cederbaum, W. Domcke, G. H. F. Diercksen, Chem. Phys. 1981, 56, 43. This paper contains a wealth of information on the Green function calculations of ionization energies.

54 D. Lenoir, Synthesis 1989, 883, and references therein.

55 M. P. Fleming, J. E. McMurry, Org. Synth. 1990, 7, 1, and references therein.

56 M. J. Frisch, G. W. Trucks, H. B. Schlegel, G. E. Scuseria, M. A. Robb, J. R. Cheeseman, J. A. Montgomery, Jr., T. Vreven, K. N. Kudin, J. C. Burant, J. M. Millam, S. S. Iyengar, J. Tomasi, V. Barone, B. Mennucci, M. Cossi, G. Scalmani, N. Rega, G. A. Petersson, H. Nakatsuji, M. Hada, M. Ehara, K. Toyota, R. Fukuda, J. Hasegawa, M. Ishida, T. Nakajima, Y. Honda, O. Kitao, H. Nakai, M. Klene, X. Li, J. E. Knox, H. P. Hratchian, J. B. Cross, V. Bakken, C. Adamo, J. Jaramillo, R. Gomperts, R. E. Stratmann, O. Yazyev, A. J. Austin, R. Cammi, C. Pomelli, J. W. Ochterski, P. Y. Ayala, K. Morokuma, G. A. Voth, P. Salvador, J. J. Dannenberg, V. G. Zakrzewski, S. Dapprich, A. D. Daniels, M. C. Strain, O. Farkas, D. K. Malick, A. D. Rabuck, K. Raghavachari, J. B. Foresman, J. V. Ortiz, Q. Cui, A. G. Baboul, S. Clifford, J. Cioslowski, B. B. Stefanov, G. Liu, A. Liashenko, P. Piskorz, I. Komaromi, R. L. Martin, D. J. Fox, T. Keith, M. A. Al-Laham, C. Y. Peng, A. Nanayakkara, M. Challacombe, P. M. W. Gill, B. Johnson, W. Chen, M. W. Wong, C. Gonzalez, J. A. Pople, Gaussian 03 (Revision E.01), Gaussian, Inc., Wallingford CT, 2004.

57 AIMAll: AIMAll (Version 16.01.09), Todd A. Keith, TK Gristmill Software, Overland Park KS, USA, 2016 (aim. tkgristmill.com). 